\title{
Phenotyping of Hybrid Maize (Zea mays L.) at Seedling Stage under Drought Condition
}

\author{
Shirin Aktar, Nilima Hossain, Mohammad Golam Azam, Masum Billah, Priya Lal Biswas, \\ Mohammad Abdul Latif, Motiar Rohman, Shamim Ara Bagum, Mohammad Shalim Uddin
}

Molecular Breeding Lab, Plant Breeding Division, Bangladesh Agricultural Research Institute (BARI), Gazipur, Bangladesh

Email: aktershirin1992@gmail.com

How to cite this paper: Aktar, S., Hossain, N., Azam, M.G., Billah, M., Biswas, P.L., Latif, M.A., Rohman, M., Bagum, S.A. and Uddin, M.S. (2018) Phenotyping of Hybrid Maize (Zea mays L.) at Seedling Stage under Drought Condition. American Journal of Plant Sciences, 9, 2154-2169.

https://doi.org/10.4236/ajps.2018.911156

Received: August 17, 2018

Accepted: October 13, 2018

Published: October 16, 2018

Copyright $\odot 2018$ by authors and Scientific Research Publishing Inc. This work is licensed under the Creative Commons Attribution International License (CC BY 4.0).

http://creativecommons.org/licenses/by/4.0/

\begin{abstract}
Drought is envisaged as the greatest demolishing natural impacts throughout the world since it has observed extensive place of agronomical land sterile almost the world. It's the significant crop output-limiting producer, and elaborated learning of its result on plant enhancement dictation is diametrical. At present, drought tolerant hybrid maize has been trying to induce Bangladesh especially drought affected zone to identify the drought endurance maize genotypes. Consequently, a feasible pot study of 49 hybrid maize genotypes were directed to determine an adequate drought level to promote aliment and promotion of maize plant below the water stress conditions with treatment (control and drought) and three replications. The data were received after 35 days of sowing using appropriate procedures. Specially, the stomata were collected by the white transparent nail polish from the lower part of leaves. Descriptive statistic of the all traits like percentage of SPAD, leaf rolling (LR), maximum root length (MRL), maximum shoot length (MSL), root dry matter (RDM), shoot dry matter (SDM), length of stomata (LS), width of stomata (WS), thickness of stomata (TS), total dry matter (TDM) and ANOVA for control and drought condition individually showed significant $(\mathrm{P}<0.05)$ variations among the germplasm for their genotypes, treatment and interaction. The first fourth principal components (PCs) narrated about $82.0 \%$ of the total variation. Cluster analysis placed the 49 hybrid into 6 main groups among those cluster; groups five showed the maximum number mean value of traits. The highest positive relationship was obtained from TS, WS, RDM, SDM and TDM traits by forming genotype-traits bi-plot of 11traits of 49 genotypes. After analyzing, it is explicit that G18 (CML-80 $\times$ IPB911-16) and G22 (CZI-04 $\times$ IPB911-16) were the most tolerant hybrids maize genotypes and very susceptible hybrids maize genotypes were G16 (P-12 × CML487), G34 (CML-32 × PB911-16) and G37 (P-33 × CML487). It is expected that the higher expression of considered traits might be obligate
\end{abstract}


for better yield under drought stress.

\section{Keywords}

Maize, Stress, Drought, Phenotypes, Tolerant

\section{Introduction}

Maize is the third largest crops of Bangladesh following wheat and rice. Despite considerable significance of maize as food, forage and oil, few studies had been focused on the selection of maize germplasm to appraise its drought or water stress tolerance [1]. The demand of the raising population with increasing food and energy are full-filled by the expanding global maize production [2].

This is predominantly because of great need of maize, peculiarly for poultry. Farmers always want to cultivate profitable and low risk crop [3]. Under these condition, yields of staplecrop plants like bread wheat (Triticum aestivum), rice (Oriza sativa), and maize (Zea mays), which provide over $50 \%$ of human calories, are predicted to decrease [4]. It provides a major food resource for peoples. It is the principal emergence of energy and protein in the diet of many people. It prevents constipation and reduces stomach acidity, diabetes and heart diseases. It combats the certain cancers [5]. But the security abundance of crop production decreases day by day because of diverse types of natural hazard such as flood, drought, salinity etc. [6].

Drought is the main abiotic stress in Bangladesh that limits the productivity of maize crop. It is one of the natural hazards in Bangladesh especially northern part. Again, maize is the profuse uses cereal crops in agriculture of Bangladesh. It's also called the "Life Blood" [7]. According to Rabi season and Kharif season, the most significant drought prone area in Bangladesh was formed in $8.66 \%$ and $2.47 \%$ per decennary [8]. In accordance with the statistics well-nigh, $47 \%$ of the country and at that time nearing $53 \%$ of the demography are endured by the vastly invaded food production [9]. Globally, the yearly retrenchment of maize yield caused by drought is estimated around 15\%, illustrating crop reduces of more than 20 (MT) million tones in grain [10].

Various plant structural differences that are troublesome to repercussion to drought condition, dispose from morphologic acclimatization (spill in growth rate, dense rooting method) and alternation of root-shoot proportion for abstinence of desiccation as phenological reactions stomata (closure, antioxidant accumulation, and stress appointed genes manifestation) [11]. The characters such as root length, root dry weight, root density, leaf temperature and shoot dry weight that inferred to have performance to maize seedling's shoot length. The moisture level was maintained that create water stress by volume on alternate days by using moisture meter [12].

Numerous genes those react for drought condition are exposed by general 
seed maturation, can be inaugurated in incomplete embryos and unaccented vegetative tissues by the exogenous uses of ABA [13]. The yield of maize greatly minimizes the tangible stress in root hair elongation [14]. The outcome of water-deficit stress on the cell allocation in themeristem of initial root of maize plant seedlings and terminated that water-deficit condition produced meristem cells to be prostrate and cell fissionminimize towards with per unit length of tissues and cell in entire the meristem [15].

Though shoot growth reduced completely more than root growth by inaugurated osmotic stress conditions, drought injury index united surely and significantly to root shoot ratio [16]. Although water-deficit condition suppressed both shoot and root growth, shoot growth was more impressible than root growth, in this way shoot-root was typically attenuated [17]. For diminishing the outcome of cold stress on plant redaction assessed the seed vigor, germination and germination index at close-to-optimum stresses. However, there was operative alteration in these characters, which gave us with the probability to inquire their genetic control [18].

Plant height was decreased by drought stress. For alteration of hormonal intentness was influenced the plant height by the imputed the drought stresses. By lowering the cell wall ductility, the plant growth significantly influenced it such as Cytokines and Abscise acid [19]. For changing in plant water condition influences the leaf elongation in maize immediately and is highly impressionable [20]. Because of retrenchment of cell turgidity, the leaf area was greatly minimized by the water stress that may sake prohibition of cell elongation [19]. The plant's age was normally increased by the SPAD value but water-deficit condition greatly attenuated SPAD value at both the vegetative and reproductive periods. Assimilation rate was minimized by the low temperatures due to attenuate the mode of the Rubisco and of the receptivity for electron transport. The stomatal restriction of photosynthesis is mostly thought of as much the performance of stomatal counteraction to some total "resistance" to the $\mathrm{CO}_{2}$ elevation [21]. The unfavorable outcomes of drought condition might also reduce by confirming more appearance of water to the plant body by the incomplete closure of the stomata during transpiration [19]. Drought causes in a fall of cell turgor and in the variation of cellular components that possibly the unstable of the various membrane methods, protein amount and breakdown of general metabolism [13].

Because of the reduction in turgor pressure, cell growth is the main drought-impressible physiologic method [22]. In accession, temperature dramatically changed the stomatal local ordination model with a muscular improvement of the mean closest neighbor range between stomata on both ad axial and abbatial faces [23]. The abbatial surface is raised more than the ad axial leaf surfaces in both traits by the stomatal inhibition. This was joined with the alterations in leaf form or rolling inside of the upper leaf surface. Both reaction of stomatal inhibition and leaf rolling, were inaugurated in a resembling leaf water expectation range ( -8 to -12 bars) [24].

Normally, growth parameter such as plant height, fresh and dry weight of 
shoot and relative water volumes and photosynthesis were baldly desolated by the water stress levels. Besides, using of potassium slowly extinguished the negative outcome of water stress [25]. Drought stresses was minimized the plant fresh weight. Because of its oppressed crop growth pattern or its inappropriate location between and within the spikelet under water-deficit condition causing imbibe restriction [26]. The plant biomass was minimized by the water-deficit condition but it produce to strafe shoots more than roots [19]. However, drought affects the seedling of maize root and shoot growth, creates different environmental disorder and also affects the stomatal structure such as stomata length, stomata wide, etc.

Keeping in view of all above consideration, a drought experiment was accomplished applying 49 hybrids maize and also to uncover best drought tolerant maize hybrid that could be further applied to access its efficient on natural drought-affected soil.

\section{Materials and Methods}

Forty nine hybrid maize genotypes were applied for this research which is shown in Table 1. The phenotype was conducted in the Plant Breeding Division (green house), Bangladesh Agricultural Research (BARI), and Gazipur-1701 for drought culture, where heat was conserved at $28^{\circ} \mathrm{C}-30^{\circ} \mathrm{C}$ for 14 hours into light and at $22^{\circ} \mathrm{C}$ for 10 hours under dark conditions. The severity of light and the relative humidity of the greenhouse were maintained $657 \mu$ mole $\mathrm{m}^{-2} \mathrm{~s}^{-1}$ and $50 \%$ respectively. The Split plot RCBD, particularly, two treatments (control and drought) were applied and each treatment run through two replications to conducts the experiment by the year January 4th to February 10th.

Table 1. Name of the hybrid and their identified genotypes.

\begin{tabular}{cc}
\hline Identification of Genotypes & Name of the variety \\
G1 & CML-14 $\times$ IPB911-16 \\
G3 & P-77 $\times$ CML487 \\
G4 & CZI-33 $\times$ CML487 \\
G5 & P-88 $\times$ CML487 \\
G6 & CML-5.4 $\times$ CML487 \\
G7 & P-152 $\times$ CML487 \\
G8 & IPB-911-36 $\times$ IPB911-16 \\
G9 & P-83 $\times$ CML487 \\
G10 & P-05 $\times$ CML487 \\
G11 & P-80 $\times$ IPB911-16 \\
G12 & P-20 $\times$ IPB911-16 \\
G13 & P-10 $\times$ CML487 \\
G14 & CZI-19 $\times$ CML487 \\
\hline
\end{tabular}


Continued

\begin{tabular}{|c|c|}
\hline G15 & CZI-26 × CML487 \\
\hline G16 & $\mathrm{P}-12 \times$ CML 487 \\
\hline G17 & P-20 × IPB911-16 \\
\hline G18 & CML-80 × IPB911-16 \\
\hline G19 & CML-15 × CML487 \\
\hline G20 & P-15 × IPB911-16 \\
\hline G21 & CZI-37 × CML487 \\
\hline G22 & CZI-04 × IPB911-16 \\
\hline G23 & CML-509 × CML487 \\
\hline G24 & CML-16 × IPB911-16 \\
\hline G25 & $\mathrm{P}-15 \times$ CML 487 \\
\hline G26 & CML-94 × CML487 \\
\hline G27 & CML-192 × IPB911-16 \\
\hline G28 & P-01 $\times$ CML487 \\
\hline G29 & P-69 $\times$ CML487 \\
\hline G30 & P-7 $\times$ IPB911-16 \\
\hline G31 & P-21 $\times$ IPB911-16 \\
\hline G32 & P-42 $\times$ CML 487 \\
\hline G33 & $\mathrm{P}-16 \times$ CML 487 \\
\hline G34 & CML-32 × IPB911-16 \\
\hline G35 & P-16 × IPB911-16 \\
\hline G36 & CML-481 × CML487 \\
\hline G37 & $\mathrm{P}-33 \times \mathrm{CML} 487$ \\
\hline G38 & $\mathrm{P}-81 \times$ CML 487 \\
\hline G39 & CZI-17 × CML487 \\
\hline G40 & P-55 × IPB911-16 \\
\hline G41 & $\mathrm{P} 140 \times \mathrm{CML} 487$ \\
\hline G42 & CML-94 × IPB911-16 \\
\hline G43 & CML-11 × IPB911-16 \\
\hline G44 & CML-18 $\times$ CML487 \\
\hline G45 & $\mathrm{P}-10 \times$ CML 487 \\
\hline G46 & IPB-911-02 × IPB911-16 \\
\hline G47 & CZI-30 × IPB911-16 \\
\hline G48 & CZI-26 × IPB911-16 \\
\hline G49 & CML-15 × IPB911-16 \\
\hline
\end{tabular}


A pot experiment was led from 4th January to mid-February 2017 applying 49 hybrid maize genotypes control and treatment respectively. In the current experiment, two replications were moved in two factorial arrangement by the Split Plot RCBD. All 196 plastic pots were used and loaded with $300 \mathrm{~g}$ soil per pot. All 196 plastic pots were taken and filled with $300 \mathrm{~g}$ soil per pot. Four seeds of maize were woven on 4th January 2017 baldly in plastic pot. Then, four seeds of maize were woven on 4th January 2017 baldly in plastic pot. Water was applied to each pot at the rate of 0.6 litter per pot daily for 7 days and the plants were left without watering for the rest of the experiment period. Seedling emergence was assessed go-off from 4 DAS (days after sowing) till 7 DAP (days after planting). Thereafter thinning was done after 10 days of keeping one healthy seeding uniform growth in each pot.

Two sets of seedling were risen; 98 seedlings were grown for treatment and another 98 seedlings were risen for control imposition at vegetative stage. For retaining the pots from free of weeds and for better to sustain standard growth of seedling, then weeding and loosening of soil were done. The control sets of seedlings were watered to entire pot receptivity due to promote root development from germination to seedling stage ( 35 days of emergence).

One set was treated as control and another as drought stress from both stages of two sets of plants. In the experiment the well-watered controlled pots were retained at entire pot receptivity. The wetness retain of water-deficit pots were conserved and orderly monitored by reposing the soil moisture level identical to $50 \%$ field capacity.

The plant leaves exposed rolling and wilting symptoms which reported the plant were under stress due to its lowest field capacity. When the irrigation was stopped, then the plants were noticed and reading were taken on seedling height (SHT), number of leaf rolling per plant (LR), SPAD value, number of stomata (NS), width of stomata (WS), and length of stomata (LS).

The plants with the ball of soil were carefully shifted from every pot and roots cleaned free of sand by a soft running tap after 35 days of experimental time. The roots were separated from the shoot at the cotyledonal node. The length of primary root and shoot (RL and SL in $\mathrm{cm}$ ) were taken by a meter rule. Again, shoot dry matter $(\mathrm{g})$ and root dry matter $(\mathrm{g})$ were surveyed by a weighting balance.

Dry weight was measured by taming plant tissue sample to oven drying at $65^{\circ} \mathrm{C}$ until a satisfied weight was attained.

\section{Statistical Analysis}

STAR (Statistical Tool for Agricultural Research) version: 2.0.1 which manifested by IRRI, 2014 was applied to execute the Analysis of variance (ANOVA) and cluster analysis for different characters. RCBD (Completely randomize block design) was used for individual and combined analysis of variance of with two replications was applied and, the statistical analyses were performed applying R-statistics software Version 3.1.2 for window (R Development Core Team, 2013). 


\section{Results and Discussion}

Analysis of variance (ANOVA) severally displayed great significant change within the genotypes and acts for all the envisaged traits and also ANOVA for entire the traits expressed greatly significant variations within the genotypes to the NC and DC with treatments for the interaction composition by treatment (Table 2). DC stress impacted the trait experiment in these research, the plants were smaller under DC treatment assimilated to the NC. In the box plot, the above and under quintile were displayed by the box verges and median was displayed by the middle of the box (Figure 1 and Figure 2). Particulars declining beyond the state of sideboards are exhibited as circles. Whole the traits capacitated with usual allocation in both DC and NC stress without some traits skewed left and some are right.
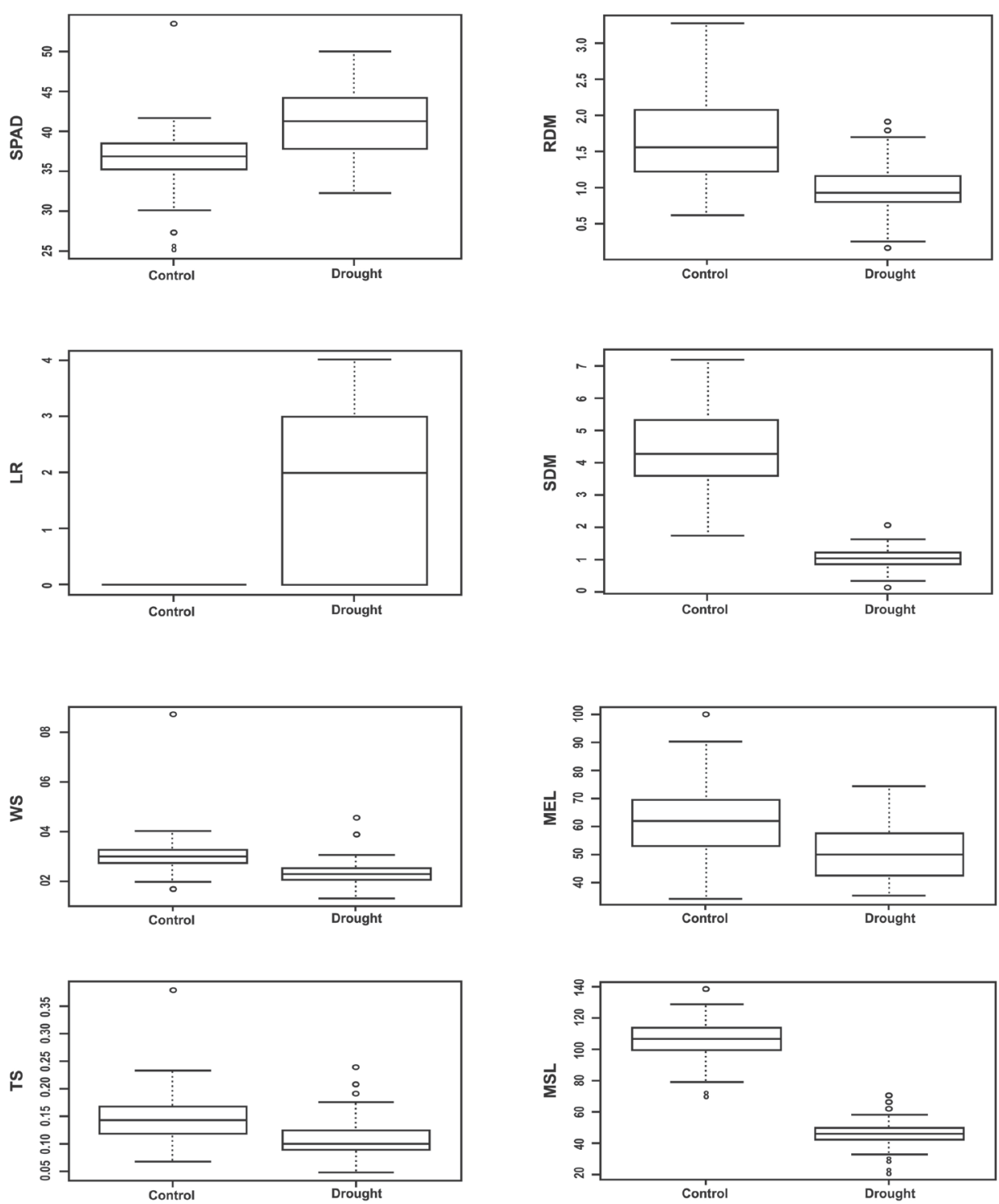

Figure 1. Box plots display variances under control and drought stresses for SPAD, RDM, LR, SDM, WS, TS and MSL. 

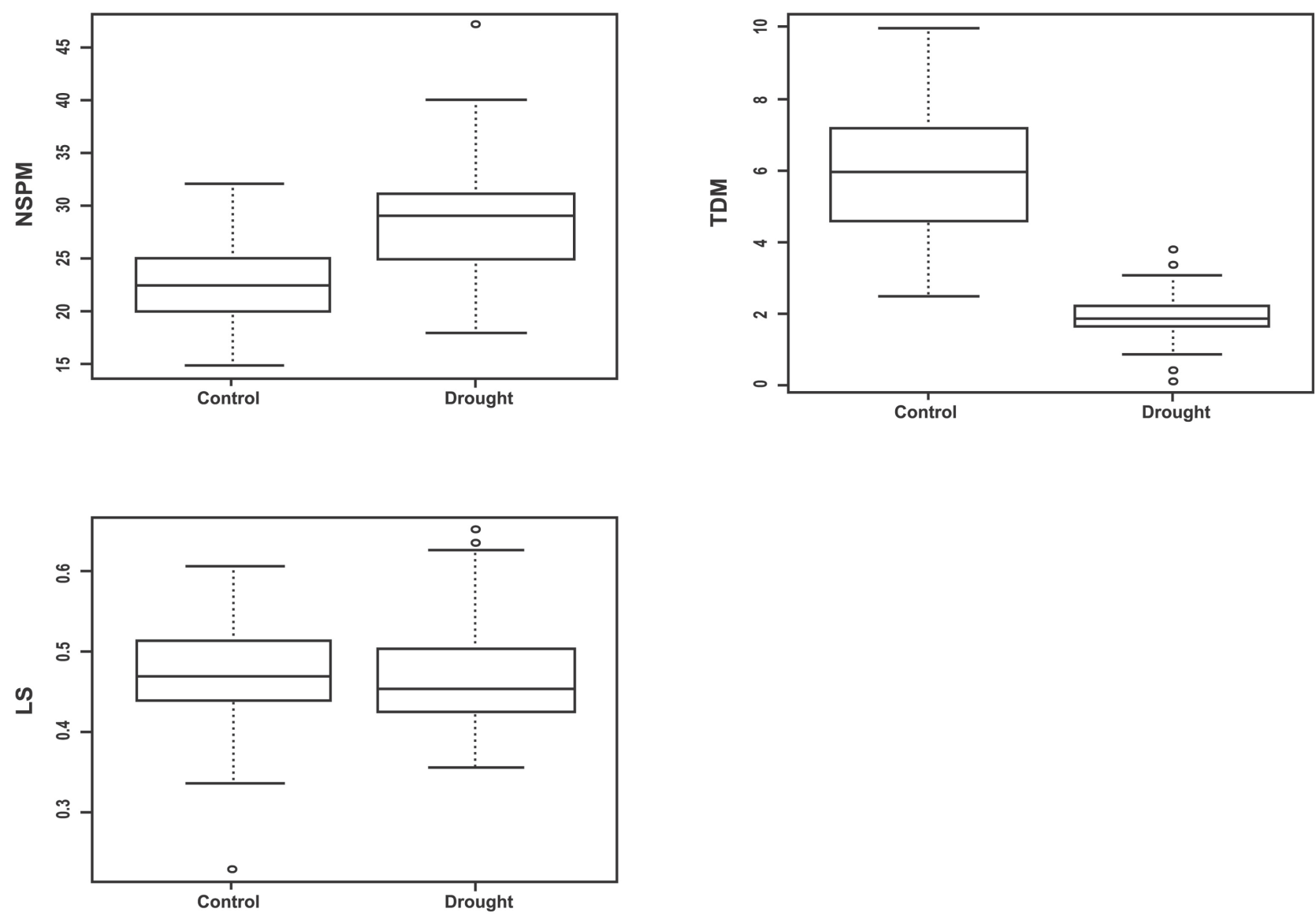

Figure 2. Box plots display variances under control and drought stresses for NSPM (number of stomata/8.16 mm²), TDM, and LS.

Table 2. Combine ANOVA (analysis of variance) of the traits determined.

\begin{tabular}{|c|c|c|c|c|c|c|c|c|c|c|c|c|}
\hline \multirow{2}{*}{$\begin{array}{l}\text { Source of } \\
\text { variation }\end{array}$} & \multicolumn{12}{|c|}{ Mean square } \\
\hline & df & SPAD & LR & MRL & MSL & $\mathrm{RDM}$ & SDM & NS & LS & wS & TS & TDM \\
\hline Replication & 1 & 33.14 & 0.25 & 6.61 & 17.76 & 0.02 & 0.46 & 7.36 & 0.001 & 0.0006 & 0.00 & 0.28 \\
\hline Treatments & 1 & 1008.52 & $128.98^{* *}$ & $5689.47^{\star *}$ & $173353.27^{*}$ & $21.41^{* *}$ & $547.16^{* *}$ & 1444.0 & $0.0056^{* *}$ & $0.26^{*}$ & 0.06 & $785.05^{* *}$ \\
\hline Error (a) & 1 & 24.57 & 0.25 & 5.89 & 432.05 & 0.02 & 1.19 & 73.47 & 0.002 & 0.001 & 0.0008 & 1.48 \\
\hline Genotypes & 48 & $27.07^{\star *}$ & $1.26^{* *}$ & $7090.20^{\star *}$ & $152.93^{* *}$ & 0.36 & 1.23 & $32.36^{* *}$ & 0.01 & $0.0045^{\star}$ & 0.0029 & 2.24 \\
\hline $\begin{array}{c}\text { Genotypes } \times \\
\text { Treatment }\end{array}$ & 48 & $18.03^{* *}$ & $1.26^{* *}$ & $6844.53^{*}$ & 103.86 & 0.39 & 1.17 & 23.78 & 0.0028 & 0.0047 & $0.0013^{* *}$ & 2.52 \\
\hline Error (b) & 96 & 8.96 & 0.32 & 75.82 & 76.54 & 0.10 & 0.45 & 12.72 & 0.002 & 0.003 & 0.0008 & 0.73 \\
\hline Total & 195 & & & & & & & & & & & \\
\hline
\end{tabular}

$\mathrm{NC}=$ Normal condition, $\mathrm{DC}=$ Drought condition, $\mathrm{MSL}=$ Maximum shoot length $(\mathrm{cm}), \mathrm{MRL}=$ Maximum root length $(\mathrm{cm}), \mathrm{SDM}=\mathrm{Shoot}$ dry matter $(\mathrm{g})$, RDM = Root dry matter $(\mathrm{g}), \mathrm{NS}=$ Number of stomata $\left(\mathrm{mm}^{2}\right), \mathrm{LS}=$ Length of stomata $(\mathrm{mm})$, WS $=$ Width of stomata $(\mathrm{mm})$, TS $=$ Thickness of Stomata $\left(\mathrm{mm}^{2}\right), \mathrm{TDM}=$ Total dry matter $(\mathrm{g}),{ }^{\mathrm{NS}}$ Not significant; ${ }^{* *}$ Significant at the 0.01 level of probability, ${ }^{*}$ Significant at the 0.05 level of probability.

\subsection{Genotype by Trait Interactions}

A two-way form of genotype-traits bi-plot displayed the comparative value of the traits which was being prepared from the 10 parameters and 49 genotypes (Figure 3). The reports from this matrix into essential elements were concen- 
trated by the plot. The plots displayed the relevance within traits. The cosine of the angle within the vectors cohesive characters due to the provenance is proportionated to the correlation coefficient within that traits (Yan and Kang, 2003). In this way, traits on converse sides of the paternity are negatively correlated, traits close one another are positively correlative, and traits at $90^{\circ}$ to one another with fear on account of the origin are not correlative. Genotype by traits bi-plot displayed best genotypes with comparatively better exposure of combinations of respectable traits. The outcomes report that TS, WS, MRL, MSL, SDM, RDM and TDM could identify best genotypes in prime germplasm.

\subsection{Cluster Analysis for Classification of Hybrids Maize Genotypes}

The cluster analysis was accomplished with comparative traits values of every trait. The whole maize hybrids genotypes founded on the seedlings traits calculated the Euclidian distance coefficients. The forty nine genotypes into 6 major groups were settled by the cluster analysis. The first cluster composed of 7 genotypes (G1, G35, G36, G38, G43, G45, G49), second cluster turned with 12 genotypes (G2, G10, G11, G12, G13, G15, G19, G23, G25, G32, G40, and G47), third cluster lied on 17 genotypes (G3, G4, G5, G6, G7, G8, G9, G14, G17, G20, G26, G27, G28, G29, G30, G31, and G44), fourth cluster consisted with 7 genotypes (G16, G34, G37, G39, G41, G42, and G46), fifth cluster formed by 4 genotypes (G18, G22, G24, and G48), and six cluster formed by 2 genotypes (G21 and G33).

Within the cluster group, the greatest number mean value for SPAD, MSL, MRL, LS, SDM (near to 1) and TDM were demonstrated (cluster group mean Table 3) by six number cluster group. It's given that six number cluster group was greatest tolerant genotypes pursued by cluster group six it's shown highest mean for SPAD, MSL, MRL, NS, RDM, closed the TDM with cluster number five and near mean to the cluster five. It's proved that cluster group six was medium tolerant. The smallest mean value displayed in the cluster number four, this group shown low value in SDM, MRL, RDM and TDM, it's reported that genotypes comes from the cluster number four were prehensile.

Table 3. Cluster groups and their containing genotypes name applying Euclidean genetic distance based on all seedling traits measured.

\begin{tabular}{ccc}
\hline Cluster & Size & The Genotype's Name \\
\hline I & 7 & G1, G35, G36, G38, G43, G45 and G49 \\
II & 12 & G2, G10, G11, G12, G13, G15, G19, G23, G25, G32, G40, and G47 \\
III & 17 & G3, G4, G5, G6, G7, G8, G9, G14, G17, G20, \\
IV & 7 & G26, G27, G28, G29, G30, G31, and G44 \\
V & 4 & G16, G34, G37, G39, G41, G42, and G46 \\
VI & 2 & G18, G22, G24, and G48 \\
\hline
\end{tabular}




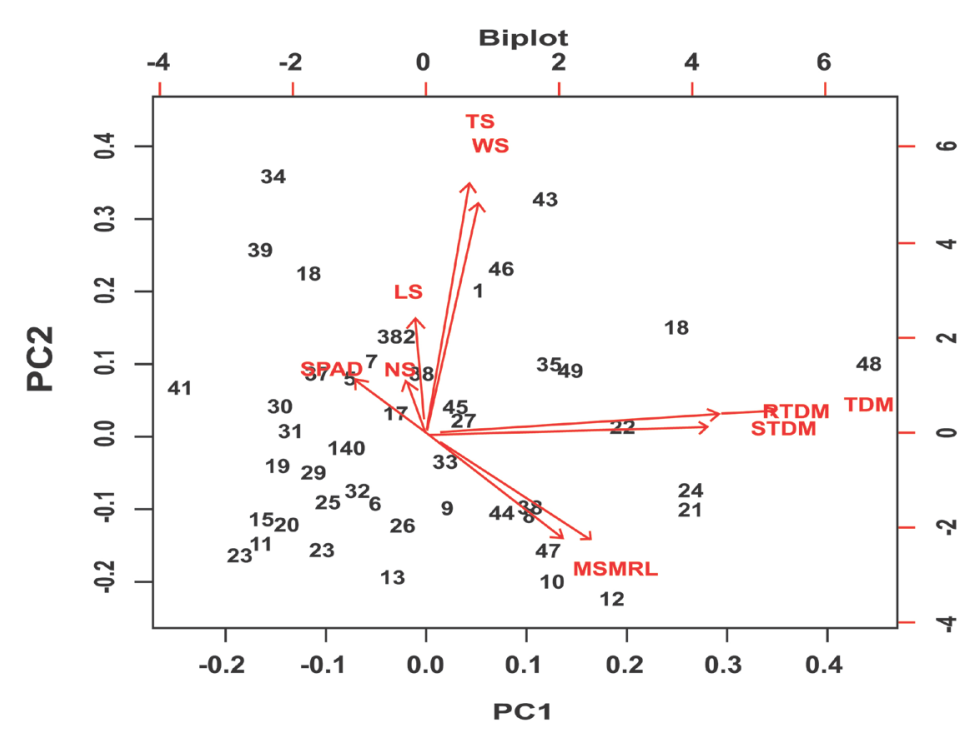

Figure 3. Genotype-trait bi-plot based on seedling traits of maize.

The current experiment explored that the outcome of drought or water scarcity on growing of the 49 maize hybrid genotypes. The data exposed that drought had greatly influenced the all experiment parameters without RDM (Table 2). Due to drought treatment the calculation of green leaves rolling increased and of all hybrids and wilting was occurred of maximum hybrids; because drought attenuated osmotic potential and enhancement ionic toxicity.

Similar espial has been found by the experiment of the upshot of potassium on plant height of maizehybrids genotypes were grown under different drought conditions at various selected growth stages [19] [26]. They are revealed that, drought stress enhancement the wilting and leaf rolling.

Few genotypes noticed higher SPAD value under drought treatment than control treatment in our experiment. Drought effect decreased the seedling growth by significantly decreased the chlorophyll quantities (SPAD value) and area of leaf to all hybrids which ultimately decreased plant growth as similar result from found the previous experiment [19]. Though, genotypes comes from the cluster I, III and IV shown superior SPAD values over control (Table 3 and Table 4), [27] in an experiment on the three stress patterns decided by three cluster analysis covered a closely stress-free environment (L), a mild, mid-season stress pattern including both the reproductive and early grain filling periods (M), and acute drought happening by the late reproductive period (SR). [28] noted five cluster in maize.

In the current experiment, relative mean value data expressed that drought treatment onward the calculation of green leaf rolling of all hybrids genotypes (Table 3).

Euclidian distance coefficients were enumerated for all maize hybrids based on seedling traits. Dendrogram from UPGMA clustering noticed grouping of 49 genotypes of maize into six clusters (Figure 4). Cluster I, II, III, IV, V and VI comprised with 7, 12, 17, 7, 4 and 2 hybrids, respectively (Table 3). Among the 
six cluster, cluster number III holding best tolerant genotypes for the greatest number of relative mean. Similarly espial has been found by the experiment of $\mathrm{V}$ cluster analysis on 29 maize varieties under salt tolerant condition [29] [30].

Plant height was reduced under drought stress. Similarly, noticed that water-deficit stress had harmful effects on the seedling height for whole hybrids genotypes.

Table 4. Mean values for six clusters based on ten quantitative traits of 49 maize hybrids.

\begin{tabular}{ccccccccccc}
\hline $\begin{array}{c}\text { Cluster } \\
\text { group }\end{array}$ & SPAD & MSL & MRL & NS & LS & WS & TS & SDM & RDM & TDM \\
\hline I & 0.89 & 0.48 & 0.80 & 1.16 & 0.97 & 1.54 & 1.49 & 0.31 & 0.68 & 0.42 \\
II & 0.83 & 0.48 & 0.83 & 1.16 & 0.86 & 0.78 & 0.66 & 0.20 & 0.63 & 0.31 \\
III & 0.94 & 0.43 & 0.84 & 1.33 & 1.00 & 0.80 & 0.80 & 0.24 & 0.69 & 0.35 \\
IV & 0.86 & 0.84 & 0.75 & 1.52 & 0.93 & 1.57 & 1.46 & 0.17 & 0.60 & 0.30 \\
V & 0.79 & 0.75 & 0.92 & 1.35 & 0.99 & 1.10 & 1.09 & 0.50 & 1.14 & 0.64 \\
VI & 0.79 & 0.92 & 0.81 & 1.99 & 0.82 & 0.90 & 0.73 & 0.32 & 1.09 & 0.50 \\
\hline
\end{tabular}

MSL: Maximum shoot length $(\mathrm{cm})$, MRL: Maximum root length $(\mathrm{cm}), \mathrm{NS}$ : Number of stomata $\left(\mathrm{mm}^{2}\right), \mathrm{WS}$ Wide of stomata $(\mathrm{mm})$, LS: Length of stomata $(\mathrm{mm})$, TS: Thickness of stomata $\left(\mathrm{mm}^{2}\right)$, SDM: Shoot dry matter (g), RDM: Root dry matter (g) and TDM: Total dry matter (g).

\section{Dendrogran using agglomerative Clustering Method}

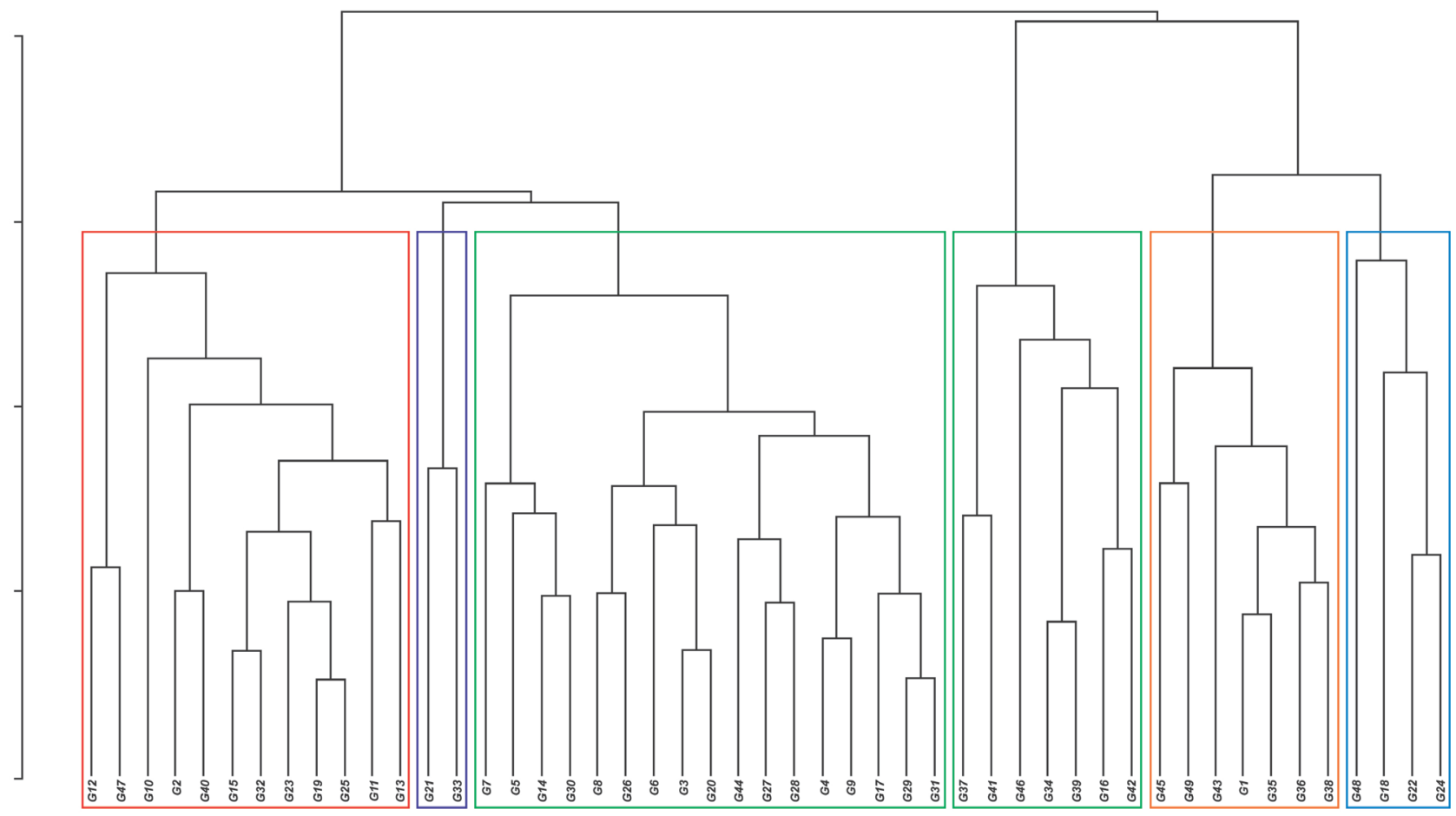

Figure 4. Dendrogram from UPGMA clustering for 49 maize genotypes applying Euclidean genetic distance based on all seedling traits measured. 
Moreover, the unfavorable outcomes of water-deficit stress might also diminished by ensuring more appearance of water to the plant body by the incomplete closure of the stomata by transpiration [17] [26]. In this experiment, the root lengths of whole hybrids genotypes improve under water-deficit condition to drought treatment. Stress of water-deficit has significant outcome on root length, but this may vary with plant categoryor genotype.

In present study, it has been observed that the stomata number were increased in drought stressed condition than the control environment. Further, the wide of stomata decreased in drought condition than control condition. Growth of cell is severely impressible to drought conditions. Similar result found on the maize by another research [28]. The maximum guard cells of plant stomata were open in control condition but the maximum guard cells of plant stomata were closed in drought condition for osmotic pressure and ionic toxicity. Similarly, turgor in whole cells was supreme for the restrictive osmotic conditions [31]. Then, the negative relationship was dappled in drought stress is known to deflect the balance of various plant hormones and modify their interactions, which can alter the function of plant stomata. The lipid-procurement hormone is also smeared as a principal player based on its collection during drought and its descriptive regulatory induction in stomatal closure [32]. Similarly, drought stress inaugurated stomata closure, are not strongly connected in the prohibition of stomata enacting by drought stress [33].

It was found that significant differences were given away within whole genotypes and drought treatment with importance to shoot length, root length and biomass production (Table 2). Under this experiment, the dry weight of root was apparently prohibited by drought stress.

Table 5. The first four principal components of trait eigenvectors in maize germplasm.

\begin{tabular}{ccccc}
\hline Variables & PC1 & PC2 & PC3 & PC4 \\
SPAD & -0.12 & 0.13 & 0.45 & -0.83 \\
MSL & 0.28 & -0.27 & -0.35 & -0.29 \\
MRL & 0.23 & -0.27 & -0.07 & 0.18 \\
NS & -0.03 & 0.13 & 0.27 & 0.11 \\
LS & -0.02 & 0.29 & 0.48 & 0.36 \\
WS & 0.09 & 0.59 & -0.39 & -0.09 \\
TS & 0.07 & 0.63 & -0.22 & 0.03 \\
SDM & 0.50 & 0.05 & -0.08 & -0.18 \\
RDM & 0.25 & 0.01 & 0.35 & 0.10 \\
TDM & 0.60 & 0.06 & 0.19 & -0.00 \\
Cumulative Proportion & 0.48 & 0.61 & 0.82 \\
\hline
\end{tabular}


Undoubtedly, drought condition declined the biomass production for the shortage of plant growth. Therefore, the maximal weight of dry root was weighted at control and the minimum dry root weight at the drought treatment. The same results were shown in various crops by many other researchers [19]. Root dry weight was also influenced by water-deficit stress and quick changes in water state which lead to decreased cell turgor or loss of water potential gradients will prohibit the root growth. In current study relative mean data revealed that water-deficit stress decreased the dry matter production on account of the retrenchment of plant growth (Table 4).

The first fourth principal components (PCs) explained about $82.0 \%$ of the total variation among genotypes for the different maize seedling traits (Table 5). The similar analysis found in [17] research and they said that the first four PC axes accounted for $82 \%$ of the total variation among the extra-early hybrids. Same results were shown in various crops by many other researchers [14] [19] [28].

\section{Conclusion}

Within the drought conditions, finding the hybrids genotypes of maize that are drought tolerant at seedling stages can be effective in reducing the impendence of poor stand induction. Replicated seedling (control and drought) of chosen parameters assimilated one another and revealed the drought lasting hybrid maize genotypes. Significant variations were track out in detected by the leave rolling, chlorophyll content, root, shoot length, number of stomata, wide of stomata, length of stomata and biomass of variant hybrids at a drought level. It was resolved that the using parameters of number of green leaves rolling, chlorophyll contents, shoot/root length, shoot/root dry weight, and stomata frequency were the serious factors under the drought patient maize hybrids at seedling stages. The current experiment delivers the guidelines and this evidence is usable and very much serious to breeders in maize that is drought tolerant to the select of drought tolerant hybrids maize genotypes. Though, further studies are required on the genetic bases of delusion. Through analysis it was terminated that G18 (CML-80 $\times$ IPB911-16) was most drought tolerant hybrids maize genotypes, followed by G22 (CZI-04 × IPB911-16) and G24 (CML-16 × IPB911-16) and very susceptible hybrids maize genotypes were G16 (P-12 $\times$ CML487), G34 (CML-32 × IPB911-16) and G37 (P-33 × CML487). In future, these hybrid maize genotypes would be applied for drought tolerant breeding program as suitable genetic components.

\section{Conflicts of Interest}

The authors declare no conflicts of interest regarding the publication of this paper.

\section{References}

[1] Bashir, N., Mahmood, S., Zafar, Z.U. and Rasul, S. (2016) Is Drought Tolerance in 
Maize (Zea mays L.) Cultivars at the Juvenile Stage Maintained at the Reproductive Stage? Pakistan Journal of Botany, 48, 1385-1392.

[2] Liu, M., Li, M., Liu, K. and Sui, N. (2015) Effects of Drought Stress on Seed Germination and Seedling Growth of Different Maize Varieties. Journal of Agricultural Science, 7, 231.

[3] Mahjabin, S. (2016) An Economic Study of Maize Production in Some Selected Areas of Bangladesh. Doctoral Dissertation.

[4] Akter, N., Islam, M.R., Karim, M.A. and Hossain, T. (2014) Alleviation of Drought Stress in Maize by Exogenous Application of Gibberellic Acid and Cytokinin. Journal of Crop Science and Biotechnology, 17, 41-48. https://doi.org/10.1007/s12892-013-0117-3

[5] Iken, J., Amusa, N. and Obatolu, V. (2002) Nutrient Composition and Weight Evaluation of Some Newly Developed Maize Varieties in Nigeria. Journal of Food Technology in Africa, 7, 27-29. https://doi.org/10.4314/jfta.v7i1.19315

[6] Scheben, A., Yuan, Y. and Edwards, D. (2016) Advances in Genomics for Adapting Crops to Climate Change. Current Plant Biology, 6, 2-10.

https://doi.org/10.1016/j.cpb.2016.09.001

[7] Klein, R.J., Eriksen, S.E., Næss, L.O., Hammill, A., Tanner, T.M., Robledo, C. and O'brien, K.L. (2007) Portfolio Screening to Support the Mainstreaming of Adaptation to Climate Change into Development Assistance. Climatic Change, 84, 23-44. https://doi.org/10.1007/s10584-007-9268-x

[8] El Sabagh, A., Hossain, A., Barutçular, C., Abdelaal, K., Fahad, S., Anjorin, F., Islam, M.S., Ratnasekera, D., KizilgeÇİ, F., Yadav, G., Yildirim, M., Konuskan, O. and Saneoka, H. (2018) Sustainable Maize (Zea mays L.) Production under Drought Stress by Understanding Its Adverse Effect, Survival Mechanism and Drought Tolerance Indices. Journal of Experimental Biology and Agricultural Sciences, 6, 282-295.

[9] Umar, A., Mohammed, S. and Adamu, I.A. (2017) Smallholder Farmers' Drought Contextual Vulnerability Assessment in the Drylands of Northwestern Nigeria. International Journal of Scientific \& Engineering Research, 8, 1486-1491.

[10] Tambo, J.A. and Abdoulaye, T. (2012) Climate Change and Agricultural Technology Adoption: The Case of Drought Tolerant Maize in Rural Nigeria. Mitigation and Adaptation Strategies for Global Change, 17, 277-292. https://doi.org/10.1007/s11027-011-9325-7

[11] Tátrai, Z.A., Sanoubar, R., Pluhár, Z., Mancarella, S., Orsini, F. and Gianquinto, G. (2016) Morphological and Physiological Plant Responses to Drought Stress in Thymus citriodorus. International Journal of Agronomy, 2016, 1-8.

[12] Ali, Q., Elahi, M., Ahsan, M., Tahir, M.H.N. and Basra, S.M.A. (2011) Genetic Evaluation of Maize (Zea mays L.) Genotypes at Seedling Stage under Moisture Stress. International Journal for Agro Veterinary and Medical Sciences, 5, 184-193. https://doi.org/10.5455/ijavms.20110608051727

[13] Ribaut. J.-M., Betran. J., Monneveux, P. and Setter, T. (2009) Drought Tolerance in Maize. In: Bennetzen, J.L. and Hake, S.C., Eds., Handbook of Maize: Its Biology, Springer, New York, 311-344. https://doi.org/10.1007/978-0-387-79418-1_16

[14] Hochholdinger, F. and Tuberosa, R. (2009) Genetic and Genomic Dissection of Maize Root Development and Architecture. Current opinion in Plant Biology, 12, 172-177. https://doi.org/10.1016/j.pbi.2008.12.002

[15] Aslam, M., Zamir, M., Afzal, I., Yaseen, M., Mubeen, M. and Shoaib, A. (2013) Drought Stress, Its Effect on Maize production and Development of Drought Tolerance through Potassium Application. Cercetari Agronomice in Moldova, 46, 
99-114.

[16] Badu-Apraku, B., Oyekunle, M., Akinwale, R. and Lum, A.F. (2011) Combining Ability of Early-Maturing White Maize Inbreds under Stress and Nonstress Environments. Agronomy Journal, 103, 544-557. https://doi.org/10.2134/agronj2010.0345

[17] Akinwale, R.O., Awosanmi, F.E., Ogunniyi, O.O. and Fadoju, A.O. (2016) Determinants of Drought Tolerance at Seedling Stage in Early and Extra-Early Maize Hybrids. Maydica, 62, M4.

[18] De Dorlodot, S., Forster, B., Pagès, L., Price, A., Tuberosa, R. and Draye, X. (2007) Root System Architecture: Opportunities and Constraints for Genetic Improvement of Crops. Trends in Plant Science, 12, 474-481. https://doi.org/10.1016/j.tplants.2007.08.012

[19] Blum, A. and Ebercon, A. (1981) Cell Membrane Stability as a Measure of Drought and Heat Tolerance in Wheat. Crop Science, 21, 43-47. https://doi.org/10.2135/cropsci1981.0011183X002100010013x

[20] Acevedo, E., Hsiao, T.C. and Henderson, D. (1971) Immediate and Subsequent Growth Responses of Maize Leaves to Changes in Water Status. Plant Physiology, 48, 631-636. https://doi.org/10.1104/pp.48.5.631

[21] Wong, S., Cowan, I. and Farquhar, G. (1979) Stomatal Conductance Correlates with Photosynthetic Capacity. Nature, 282, 424-426. https://doi.org/10.1038/282424a0

[22] Farooq, M., Wahid, A., Kobayashi, N., Fujita, D. and Basra, S. (2009) Plant Drought Stress: Effects, Mechanisms and Management. In: Sustainable Agriculture, Springer, Berlin, 153-188. https://doi.org/10.1007/978-90-481-2666-8_12

[23] Xu, Z., Zhou, G. and Shimizu, H. (2009) Effects of Soil Drought with Nocturnal Warming on Leaf Stomatal Traits and Mesophyll Cell Ultrastructure of a Perennial Grass. Crop Science, 49, 1843-1851. https://doi.org/10.2135/cropsci2008.12.0725

[24] O’Toole, J.C. and Cruz, R.T. (1980) Response of Leaf Water Potential, Stomatal Resistance, and Leaf Rolling to Water Stress. Plant Physiology, 65, 428-432. https://doi.org/10.1104/pp.65.3.428

[25] Aslam, M., Zamir, I., Shahid, M., Afzal, I. and Yaseen, M. (2013) Morphological and Physiological Response of Maize Hybrids to Potassium Application under Drought Stress. Journal of Agricultural Research, 51.

[26] Zamir, M.S.I., Aslam, M. and Javeed, H.M.R. (2015) Influence of Potassium Levels on the Phenology of Maize (Zea mays L.) Hybrids Grown under Drought Stress. Life, 13, 110-116.

[27] Ao, S. (2016) Morpho-Physiological Traits Associated with Drought Tolerance of Maize Hybrids Subjected to Different Water and Nitrogen Supply. University of Minnesota, Minneapolis.

[28] Aslam, M., Zamir, M., Afzal, I., Yaseen, M., Mubeen, M. and Shoaib, A. (2013) Drought Stress, Its Effect on Maize Production and Development of Drought Tolerance through Potassium Application.

[29] Bagum, S.A., Billah, M., Hossain, N., Aktar, S. and Uddin, M.S. (2017) Detection of Salt Tolerant Hybrid Maize as Germination Indices and Seedling Growth Performance. Bulgarian Journal of Agricultural Science, 23, 793-798.

[30] Billah, M., Latif, M., Hossain, N. and Shalim Uddin, M. (2017) Evaluation and Selection of Salt Tolerant Hybrid Maize under Hydroponics Culture. Research on Crops, 18, 481-489. https://doi.org/10.5958/2348-7542.2017.00084.5

[31] Franks, P.J. and Farquhar, G.D. (2007) The Mechanical Diversity of Stomata and Its 
Significance in Gas-Exchange Control. Plant Physiology, 143, 78-87. https://doi.org/10.1104/pp.106.089367

[32] Santelia, D. and Lawson, T. (2016) Rethinking Guard Cell Metabolism. Plant Physiology, 172, 1371-1392. https://doi.org/10.1104/pp.16.00767

[33] Yin, Y., Adachi, Y., Ye, W., Hayashi, M., Nakamura, Y., Kinoshita, T., Mori, I.C. and Murata, Y. (2013) Difference in Abscisic Acid Perception Mechanisms between Closure Induction and Opening Inhibition of Stomata. Plant Physiology, 163, 600-610. https://doi.org/10.1104/pp.113.223826

\section{Abbreviations and Acronym}

$$
\begin{aligned}
& \text { DC = Drought Condition } \\
& \text { NC = Normal Condition } \\
& \text { WS = Wide of Stomata } \\
& \text { SF = Stomata Frequency } \\
& \text { LS = Length of Stomata } \\
& \text { NS = Number of Stomata } \\
& \text { TS = Thickness of Stomata } \\
& \text { G = Genotype } \\
& \text { df = Degree of Freedom } \\
& \mathrm{P}^{\mathrm{H}}=\text { Hydrogen Ion Potentiality } \\
& \text { PCA = Principle Component axis } \\
& \mathrm{m}=\text { Meter } \\
& \mathrm{M}=\text { Million } \\
& \text { EC = Electrical Conductivity } \\
& \text { TDS = Total Dissolved Solids } \\
& \text { Mg.g }{ }^{-1}=\text { Micrograms per Gram }
\end{aligned}
$$

